\title{
Potential Utilization of Sugarcane Bagasse Ash (Scba) In Concrete - An Experimental Review
}

\author{
M.L.Brindhalakshmi ${ }^{1}$, R. Arul Nivetha ${ }^{1}$, T.Kayalvizhi ${ }^{1}$, S.Gunasekar ${ }^{2 *}$ \\ ${ }^{I}$ UG Scholar, Department Of Civil Engineering, K.S.Rangasamy College of Technology, Tiruchengode - 637215. \\ Tamil Nadu, India. \\ ${ }^{2}$ Assistant Professor, Department Of Civil Engineering, K.S.Rangasamy College of Technology, Tiruchengode- \\ 637215, Tamil Nadu, India.
}

*Corresponding author E-Mail ID: guna.skr87@gmail.com

Doi: https://doi.org/10.34256/irjmtcon67

\begin{abstract}
Sugar cane bagasse ash (SBCA) is a fibrous waste-product of the sugar refining industry. It is generated as a combustion by-product from boilers of sugar and alcohol factories. This is composed mainly by silica and this by-product can be used as a mineral admixture in mortar and concrete. This waste product is already causing serious environmental pollution which calls for urgent ways of handling the waste. On the other hand, the boost in construction activities in the country created shortage in most of concrete making materials especially cement, resulting in an increase in price. This study examined the potential use of sugarcane bagasse ash as a partial cement replacement material. In this paper, Bagasse ash has been chemically and physically characterized, in order to evaluate the possibility of their use into concrete.
\end{abstract}

Keywords: Bagasse ash, Pozzolanic material, Normal consistency, Setting time, Compressive strength.

\section{INTRODUCTION}

Bagasse is a by-product from the sugar industry and it is usually burnt at the mill to provide process power or steam. Generally, bagasse is stored prior to further processing. Utilization of industrial and agricultural waste products in the industry has been the focus of research for economical, environmental and technical reasons. Sugar-cane bagasse is a fibrous waste-product of the sugar refining industry, along with ethanol vapor. Researches all over the world today are focusing on ways of utilizing either industrial or agricultural wastes as a source of raw materials for the construction industry. These wastes utilization would not only be economical, but may also result foreign exchange earnings and environmental pollution control.

Bagasse is the matted cellulose fiber residue from sugar cane that has been processed in a Sugar mill. Previously, bagasse was burnt as a means of solid waste disposal. However, as the cost of fuel oil, natural gas, and electricity has increased, bagasse has come to be regarded as a fuel rather than refuse in the sugar mills.

X-ray diffractometry determination of composition and presence of crystalline material, Scanning Electron Microscopy/EDAX examination of morphology of particles, as well as physical properties and refractoriness of bagasse ash has been studied. 


\section{OBJECTIVES}

- The waste resources are to be used.

- The environment pollution has to be reduced.

- The usages of wastages in concrete structures.

- The cost of construction can be minimized.

- Sugar cane bagasse ash (SCBA) having high pozzolanic reactivity despite high carbon contents $(>15 \%)$.

\section{LITERATURE REVIEW}

MedjoEko, R. and G. Riskowskihas conducted study on "A PROCEDURE FOR PROCESSING MIXTURES OF SOIL, CEMENT, AND SUGAR CANE BAGASSE”. In this paper, two schemes for processing mixtures of soil, cement, and sugar cane bagasse have been investigated to determine the best way of processing house construction bricks for rural Africa. In one case, bagasse fibres were treated for removing sugar while untreated bagasse fibres were used in the other one.

Final result is, the tests carried out here show that it is not necessary to remove sugar from sugar cane bagasse when plans are made to use it as reinforcement in soil-cement. This paper shows that although the sugar content in soil-cement-untreated bagasse is higher than the critical value which hampers cement hydration in cement-based materials, unconfined compressive strength of specimens made out of these mixtures increases with increasing level of cement.

VFE Banaag et.al., have conducted study on "BAGASSE AS AN ALTERNATIVE AGGREGATE IN HOLLOW CMU". In this paper, Conventional hollow concrete masonry units (CMU) use sand as aggregate. However, there is a growing interest in utilizing alternative aggregate like bagasse, largely as a potential use for recycled materials.

Final result is, by virtue of the results presented in this research, the possibility of utilizing bagasse as an alternative aggregate to hollow CMU was established. It is seen that the addition of bagasse to the mix, within the proportions stated above, has in fact improved the hollow CMU's compressive strength. It may be said that as much as $12 \%$ of the aggregate volume may be substituted by bagasse and still attain a strength for hollow non-load-bearing CMU.

S. Suvimol and C. Daungruedeehas conducted study on "BAGASSE ASH: EFFECT OF POZZOLANIC ACTIVITY AND APPLICATION IN CEMENT USE ASPECT”. This paper reported the potential as cementations material of grinding bagasse ash. Ashes from two different sources were first studied for chemical composition and basic performance. Then, the ash from the major source was investigated in detail. The ground ash, with percentages retained on sieve no. 325 in the range of 3-28, were used as cement replacement in the range of $20-40 \%$.

From this study, some conclusions were drawn, bagasse ash from major source composed of high silica content of $83.27 \%$, calcium oxide $7.27 \%$ and alumina oxide $2.7 \%$ and LOI of $9 \%$. Variation between source, system operation and time slightly affected chemical composition and pozzolanic reactivity. Original bagasse ash was found inefficient and various particle size of ground ash, of about 5100-7800 $\mathrm{cm} 2 / \mathrm{gm}$, show the influence of different fineness on different flow ability, setting time and strength development of paste and mortar. The coarsest ash (A) yielded the lowest pozzolanic reactivity (of about $84-87 \%$ ) while of the fine ashes range between 99-108\%.

MoisesFrias et.al, have conducted study on "CHARACTERISATION OF SUGAR CANE STRAW WASTE AS POZZOLANIC MATERIAL FOR CONSTRUCTION: CALCINING 
TEMPERATURE AND KINETIC PARAMETERS”. This paper reports on the influence of calcining temperature $(800$ and $1000 \mathrm{C}$ ) on the pozzolanic activation of sugar cane straw (SCS). The reaction kinetics of SCS ash-lime mixtures were inferred from physicochemical characteristics (X-ray diffraction patterns and thermo-gravimetry analysis.

From the results reported in the current paper, the following conclusions can be made. Sugar cane straw wastes can be recycled as active additions once calcined in the temperature range of 800 or $1000{ }^{\circ}$ C.Both SCS ashes showed a very similar pozzolanic behavior and in both cases a very high pozzolanic activity was detected. However, the maximum activation of this waste is reached by calcining at $800^{\circ} \mathrm{C}$.

NuntachaiChusilp et.al. have conducted study on "DEVELOPMENT OF BAGASSE ASH AS A POZZOLANIC MATERIAL IN CONCRETE". This research examined the ash is a byproduct from the combustion of bagasse as a fuel in thermal power plants and ash was obtained from three sources.

The bagasse ashes were ground until the particles retained on a No. 325 sieve were less than $5 \%$ and between $25-30 \%$ by weight. Portland cement type I was replaced by ground or unground bagasse ash. The result is Paste containing ground ash had higher normal consistency than the control paste. Higher replacement of cement by bagasse ash resulted in higher normal consistency and longer setting times of paste. Mortar containing original ash had a higher water requirement than mortar containing ground ash. This is due to the large particle size and high porosity of the original ash.

Siripairod $\mathrm{H}$ et.al., has conducted a study on "DEVELOPMENT OF CONCRETE FLOORING TILES BY WASTES, BAGASSE ASH AND FLY ASH FOR REPLACING TYPE I PORTLAND CEMENT". In this paper the effect of wastes as bagasse ash (BA) and fly ash (FA) replacing type I Portland cement was investigated. Samples of varied amount of either BA or FA mixed with cement at $0,10,20$ and $30 \%$, respectively were prepared. Aging times were 1, 3, 7, 14, 28, 56 and 90 days for compressive strength test while 28 days for microstructure analysis by SEM and crystalline phases by X-ray diffractometry (XRD). Physical and mechanical properties of concrete flooring tiles with 0,10 and $20 \%$ of either BA or FA and $10 \%$ sand were examined. Results were shown that specimens with $10 \%$ FA had higher strength than $10 \%$ BA and also enhanced the higher bending strength of concrete flooring tiles. However, 20\% BA gave outstanding results after 28 days; it implied that the effect of BA presented the high strength of concrete but not in the early ages. This was a result of pozzolanic reaction between BA or FA acting as a pozzolanic material and $\mathrm{Ca}(\mathrm{OH}) 2$, consequently, $\mathrm{C}-\mathrm{S}-\mathrm{H}$ which was a product from the pozzolanic reaction provided cementations admixtures and higher compressive strength.

Final result is the bagasse ash and fly ash can be pozzolanic material candidates for the production of pozzolanic-cement composite materials in order to reduce cost of production with strength. The optimum parameters for the production of pozzolanic-cement composites: bagasse ash $20 \%$ by weight or fly ash $10 \%$ by weight replacing type I Portland cement.

\section{CONCLUSIONS}

Based on the experimental results of various research and subsequent discussion on the results the following conclusions are drawn:

- Workability of concrete increases by increasing the percentage of replacement of SCBA in concrete.

- The compressive strength of concrete increased at 5\% replacement of cement with SCBA.

- Further increase in percentage of SCBA results in decrease in compressive strength. 
- The tensile strength of concrete decreasing with addition of SCBA.

- The Flexural Strength of concrete prisms is maximum at 30\% replacement of SCBA (at $250^{\circ} \mathrm{c}$ single time heating and grinding).

- The weight of cubes after curing in acids is very low, so the concrete cubes shows better resistance to acids.

- The weight of cubes after curing in Alkaline solution has been increased, so the concrete cubes show better resistance to alkali solution.

Finally it can be concluded that, sugarcane bagasse ash is one of the pozzolanic material, which can be used as an effective waste material into concrete.

\section{REFERENCES}

1. Aigbodion.v.s: Potential of using bagasse ash particle in metal matrix composite, phd work on-going, department of metallurgical and materials engineering, Ahmadu Bello university, samaru, zaria, nigeria, 2008.

2. Aigbodion.v.s, Hassan.s.b, Olajide.s,o, Agunsoye.o.j, Abdulrahaman.a.s. Okafor.g.e,: The use of rice husk ash as an aggregate for foundry sand production in nigeria, proceedings of the nigerian metallurgical society (nms), (2008) annual conference \& annual general meeting, pp 16-22.

3. Ajay goyal, a.m. Anwar: Properties of sugarcane bagasse ash and its potential as cement pozzolana binder.

4. Balogun s.: Potential of cassava liquid extract as a quenching medium for ferrous metal, m.sc thesis, dept. Of metallurgical and material engineering, ahmadu Bello university, zaria, nigeria, 2009, pp 12-40.

5. Banaag, ALC canada, menes, kqsaldivar,ds lo: Bagasse as an alternative aggregate in hollow $\mathrm{cmu}$, symposium on infrastructure development and the environment december 2006, seameoinnotech university of the philippines, diliman, quezon city, philippines.

6. Ernesto villar-cociña, moisésfríasrojas, and eduardovalenciamorales.: Sugar cane wastes as pozzolanic materials: application of mathematical model.

7. Guilherme c. Cordeiro, romildo d. Toledo filho, eduardo m. R. Fairbairn, luismarcelo m. Tavares and cristiano $h$. Oliveira.:Iinfluence of mechanical grinding on the pozzolanic activity of residual sugarcane bagasse ash.

8. S.b.Hassan,t.ause and g.b.nyior Department of metallurgical and materials engineering, ahmadu bello university, samaru, zaria, nigeria, v. S. Aigbodion,: potential utilization of solid waste (bagasse ash).

9. Medjoeko, r. And g, riskowski,: “A procedure for processing mixtures of soil, cement, and Sugar cane bagasse", agricultural engineering international journal of scientific Research and development, Vol. 03, Issue. 01, 1999.

10. Moise'sfrias , e. Villar-cocina, e. Valencia-morales,: Characterisation of sugar cane straw waste as pozzolanic material for construction: calcining temperature and kinetic parameters, Eduardo Torroja Institute (Csic), C/ Serrano Galvache 4, 28033 Madrid, Spain Department Of Physics, Central University Of Las Villas, Santa Clara 54830, Cuba Accepted 28 February 2006.

11. Nuntachaichusilp, napongsatornlikhitsripaiboon and chai jaturapitakkul: Development of bagasse ash as a pozzolanic material in concrete, research paper, As. J. Energy env. 2009, $10(03), 149-159$. 
M.L.Brindhalakshmi et al. / International Research Journal of Multidisciplinary Technovation /2019, 1(6), 475-479

12. Payá .j, monzó,.j , borrachero .m v, díaz-pinzón .l, ordóñez .l m: Sugar-cane bagasse ash (scba) studies on its properties for reusing in concrete production, Journal of chemical technology \& biotechnology , 2007, volume 77 issue 3, pp. $21-32$.

13. Siripairod h, polkert s, sujjavanich s. and chaysuwan d: Development of concrete flooring tiles by wastes, bagasse ash and fly ash for replacing type i portland cement, The 3rd ACF International Conference-ACF/VCA 2008.

14. S.Suvimol and C. Daungruedee, Bagasse ash: effect of pozzolanic activity and application in cement use aspect, The 3rd international conference-ACF/VCA,2018 